\title{
Spontaneous Termination of Spinal Myoclonus after Spinal Anesthesia: A Case Report
}

\author{
Asamaporn Puetpaiboon, M.D. ${ }^{1}$, Thanyalak Amornpojnimman, M.D. ${ }^{2}$ \\ 'Department of Anesthesiology, Faculty of Medicine, Prince of Songkla University, Hat Yai, Songkhla 90110, Thailand. \\ ${ }^{2}$ Unit of Neurology, Department of Internal Medicine, Faculty of Medicine, Prince of Songkla University, Hat Yai, \\ Songkhla 90110, Thailand. \\ Received 30 August 2021 • Revised 24 October 2021 • Accepted 24 October 2021 • Published online 23 November 2021
}

\begin{abstract}
:
Spinal myoclonus following neuraxial anesthesia is extremely rare. Herein, we report on a case of spinal myoclonus after spinal anesthesia for elective colpocleisis with perineorrhaphy, in a 71-year-old woman. Sudden, brief, repetitive, and rhythmic hyperkinetic movement in both legs developed two hours after spinal injection with hyperbaric bupivacaine; which then spontaneously resolved after 45 minutes without leaving any neurologic deficit.
\end{abstract}

Keywords: spinal anesthesia, spinal myoclonus, spinal segmental myoclonus

Contact: Asamaporn Puetpaiboon, M.D.

Department of Anesthesiology, Faculty of Medicine, Prince of Songkla University, Hat Yai, Songkhla 90110, Thailand.

E-mail: asmaporn.p@psu.ac.th

Posting by Prince of Songkla University. All rights reserved.

This is an open access article under the CC BY-NC-ND license

(http://www.jhsmr.org/index.php/jhsmr/about/editorialPolicies\#openAccessPolicy). 


\section{Introduction}

Myoclonus is a hyperkinetic movement disorder defined as: sudden, brief, jerk-like muscular contractions. Spinal myoclonus describes myoclonus that originates from the spinal cord, and is classified into spinal segmental myoclonus and propiospinal myoclonus. ${ }^{1}$ Spinal segmental myoclonus is characterized by rhythmic or semi-rhythmic involuntary movements, usually $1-2 \mathrm{~Hz}$ in frequency, of one or two limbs or in the truncal muscles. ${ }^{2}$ Causes of spinal segmental myoclonus include trauma, infection, inflammation, demyelination, tumor, arteriovenous malformation, ischemic myelopathy, and spondylotic myelopathy. ${ }^{1}$ This phenomenon also rarely occurs following spinal anesthesia; wherein, it has often been called: "spinal myoclonus", in previous anesthetic case reports. ${ }^{3}$

In this report, we present a case of spinal myoclonus in an elderly woman with a history of an old collapsed lumbar vertebra, and one uneventful spinal anesthesia after the injury. Written informed consent was obtained from the patient for publication of the case report and the accompanying video.

\section{Case report}

A-71-year-old woman (weight $54 \mathrm{~kg}$, height 140 $\mathrm{cm})$ was diagnosed with vaginal vault prolapse after hysterectomy, and was scheduled for elective colpocleisis with perineorrhaphy. She had a mass bulging into her vagina, pelvic heaviness, urinary frequency, and occasional urinary incontinence for one year.

Regarding her past medical history; she has been diagnosed with asthma and allergic rhinitis when she was eight years old. She used asthmatic reliever medication once every month, and had been admitted to the hospital, due to asthmatic attacks, a couple of times per year. She had a history of two levels of lumbar vertebral collapse, after suffering a fall 20 years ago; this had been treated by painkiller medications. She still had intermittent non- radiating lower back pain when she lifted up anything heavy or walked a long distance.

She had three surgical histories: a vaginal hysterectomy for a prolapsed uterus under an uneventful spinal anesthesia 23 years ago, an appendectomy under general anesthesia 16 years ago, and repair of an inguinal hernia under uneventful spinal anesthesia 13 years ago.

Her current medications included: gabapentin, a combination tablet containing orphenadrine citrate, aspirin, and caffeine $\left(\right.$ Norgesic $\left.^{\circledR}\right)$, theophylline, cetirizine, budesonide, a formoterol inhaler $\left(\right.$ Symbicort ${ }^{\circledR}$ ) and a berodual inhaler. Preoperative physical examination showed neither neurologic deficits, nor back deformity.

Choices of anesthesia were discussed with the patient, and she agreed with spinal anesthesia to avoid an asthmatic exacerbation. She did not receive sedative medication. In the right lateral decubitus position, spinal anesthesia was performed at the L3-L4 intervertebral space, using a 27 G Quincke spinal needle. This was successful after three attempts of spinal needle insertion without paresthesia: one attempt via a midline approach and two attempts via a paramedian approach. Ten milligrams of $0.5 \%$ hyperbaric bupivacaine (Marcaine Spinal 0.5\% Heavy, Aspen, France) was freely injected into the subarachnoid space. The dermatome level of anesthesia and analgesia was $\mathrm{T} 12$ and $\mathrm{T} 7$, respectively. The patient was placed in the lithotomy position. After one hour of an uneventful surgical procedure, she was able to move both feet and ankles; thereafter, she was transferred, bypassing the post anesthetic care unit, to the general ward. The anesthesia level was below T12 dermatome.

Two hours after the spinal injection, she developed involuntary repetitive, rhythmic, hyperkinetic jerk-like movement in both legs (shown in Video 1). The patterns of abnormal movement randomly changed between episodes, with each episode lasting from 30 seconds to one minute. The frequency and amplitude of movements gradually 
increased, and became more prominent on the left side. This repeatedly occurred for 45 minutes, and then spontaneously resolved when the anesthetic effect of spinal anesthesia disappeared. She was conscious, calm and did not receive medication to terminate the movements.

Neurological examination, after the abnormal movements subsided, showed neither motor weakness nor sensory deficit. Deep tendon reflexes of all extremities were normal. Clonus was negative and Babinski's sign was absent. Bladder and bowel control remained intact. At this point a neurologist was consulted, and observation was suggested, because the symptoms had completely terminated. She was discharged on postoperative day two, and came to follow up at the gynecological clinic four months later without complaint of any abnormal neurological symptoms.

Video 1 Repetitive, rhythmic, hyperkinetic jerk-like movement in both legs developed two hours after spinal anesthesia with hyperbaric bupivacaine. Please click here to download this Video.

\section{Discussion}

We want to add one more case report of transient hyperkinetic jerk-like movement disorder following spinal anesthesia. This is an extremely rare neurologic sequela, and is also not well recognized; because it is not mentioned in the standard textbook of anesthesiology. ${ }^{4}$ In previous reports, this event is mostly termed as: "spinal myoclonus".

Spinal myoclonus following neuraxial anesthesia is classified as segmental spinal myoclonus; which means it originates from one or a few adjacent segments of the spinal cord. $^{2}$ Typical characteristics of segmental spinal myoclonus are rhythmic or semi-rhythmic movements involving one or two limbs. ${ }^{2}$

Spinal myoclonus, following neuraxial anesthesia, typically occurs during block regression. The movement characteristics are varied among reports, and have been reported as: occasional myoclonus, rhythmic jerk, tonic clonic movement, and also bicycle riding patterns. ${ }^{5-8}$ In this present case, it was a rhythmic pattern, with gradually increasing frequency and amplitude; which was similar to many reports. ${ }^{7,8}$ The mutual characteristic is that it was completely resolved without leaving any long term neurological deficits. ${ }^{3}$

Pathophysiology of spinal myoclonus following neuraxial anesthesia remains unclear. It is hypothesized that segmental spinal myoclonus occurs from loss of inhibitory control of spinal interneurons, loss of blockage from suprasegmental descending routes or loss of inhibition from the cortex; resulting in aberrant axon hyperactivity and hyperexcitement of anterior horn cells. ${ }^{1,2,9}$ Moreover, spinal anesthesia may irritate the spinal cord causing repetitive discharges from anterior horn cells. Regarding this mechanism, the onset time of spinal myoclonus occurs during the regression of anesthetic effects.

Spinal myoclonus post neuraxial anesthesia is unpredictable, and due to a limited number of reported cases, risks of spinal myoclonus following neuraxial anesthesia are not well known. Shiratori et al. recently reviewed 23 previous reports of spinal myoclonus following neuraxial anesthesia; wherein, the events occurred after either spinal anesthesia or epidural anesthesia. There were no specific types, baricity and additives of local anesthetic that were clearly associated with spinal myoclonus following spinal anesthesia. Most of the reported cases were in women $(72.7 \%)$. The hypothesis is that women have a shorter lumbar spine as well as more curvature of lumbar spine lordosis; hence, during the elimination phase concentrations of local anesthetics differ more between the thoracic and lumbar spinal neurons. ${ }^{3}$

General anesthesia is generally preferred in patients with fractures of the vertebral column. Literature regarding the safety of spinal anesthesia in these patients is limited. Gurujala et al reported on the outcomes of 19 patients with 
recent (i.e., less than 1 month) stable vertebral column injury without primary spinal cord injury having undergone surgery under neuraxial anesthesia. None of these patients had neurological adverse events. ${ }^{10}$ In this patient, spinal myoclonus appeared unrelated to her old spinal pathology, because it resolved without neurological deficit; additionally, the time course of the symptoms apparently correlated with the local anesthetic effect.

Magnetic resonance imaging of the spine is the investigation of choice to exclude structural lesion of spinal segmental myoclonus ${ }^{2}$. However, it was not requested in this case, because the symptoms were completely resolved. From previous reports of spinal myoclonus after spinal anesthesia results of magnetic resonance imaging of the spine and brain, electroencephalography and electromyography at 48 hours after events, revealed no abnormalities. ${ }^{5,7}$

Spinal myoclonus after spinal anesthesia can be spontaneously resolved, with most of the reported cases being resolved within a day. ${ }^{3}$ Anti seizure medications were occasionally required. Although, it was successfully treated by a single dose of intravenous midazolam and sodium valproate ${ }^{7,11}$, this could have beeen a result of either medication effect or coincidence of spontaneous termination. ${ }^{11}$

Lee at el. reported a case of recurrent spinal myoclonus after repeated spinal anesthesia in one year. Although, the long term neurologic complications have not been reported. Spinal anesthesia in a patient with a history of spinal myoclonus should be avoided. ${ }^{6}$

\section{Conclusion}

In conclusion, we present a case of spinal myoclonus that occurred following spinal anesthesia with bupivacaine; which is a rare, unpredicted and self-terminating neurological complication.

\section{Funding sources}

None

\section{Conflict of interest}

The authors have no conflicts of interest to declare.

\section{References}

1. Levy A, Chen R. Myoclonus: pathophysiology and treatment options. Curr Treat Options Neurol 2016;18:21.

2. Termsarasab P, Thammongkolchai T, Frucht SJ. Spinalgenerated movement disorders: a clinical review. J Clin Mov Disord 2015;2:18.

3. Shiratori T, Hotta K, Satoh M. Spinal myoclonus following neuraxial anesthesia: a literature review. J Anesth 2019;33: 140-7.

4. Brull R, Macfarlane AJ, Chan VW. Spinal, epidural, and caudal anesthesia. In: Gropper MA, Cohen NH, Eriksson LI, Fleisher LA, Leslie K, Wiener-Kronish JP, editors. Miller's anesthesia. $9^{\text {th }}$ ed. Philadelphia: Elsevier; 2020; p.1440-2.

5. Abrão J, Bianco MdP, Roma W, Krippa JEdS, Hallak JE. Spinal myoclonus after subarachnoid anesthesia with bupivacaine. Rev Bras Anestesiol 2011;61:619-23.

6. Lee JJ, Hwang SM, Lee JS, Jang JS, Lim SY, Hong SJ. Recurrent spinal myoclonus after two episodes of spinal anesthesia at a 1-year interval -a case report. Korean J Anesthesiol 2010; 59(Suppl):S62-4.

7. Sanjoaquín M, Martínez-Quiñones J, Teixeira C, Lalanza $P$, Issa R. Spinal myoclonus following spinal anesthesia. Internet J Anesth 2008;19.

8. Shiratori T, Hotta K, Satoh M, Kondo N, Ikeda J, Sasao S. A case of spinal myoclonus in a patient with elective cesarean section. JA Clin Rep 2018;4:47

9. Cassim F, Houdayer E. Neurophysiology of myoclonus. Neurophysiol Clin 2006;36:281-91.

10. Gurajala I, Iyengar R, Durga P, Gopinath R. Spinal and epidural anesthesia in patients with recent stable fractures of vertebral column. J Neurosurg Anesthesiol 2016;28.

11. Nakamoto T, Hirota K, Iwai T, Shingu K. Complete resolution of myoclonus-like involuntary movements under subarachnoid block after midazolam administration in a patient undergoing cesarean section: a case report. Korean J Anesthesiol 2015;68: 193-5. 